\title{
TOWARDS AN ANALYSIS METHODOLOGY FOR IDENTIFYING ROOT CAUSES OF POOR DE- LIVERY PERFORMANCE
}

\author{
Peter NIELSEN ${ }^{1}$, Ngoc Anh Dung DO*, Thomas ERIKSEN**, Izabela NIELSEN* \\ *Aalborg University, Department of Mechanical and Manufacturing Engineering, Denmark \\ e-mail: peter@m-tech.aau.dk \\ **CS BtB Operations Center, Telenor ASA Group, Denmark
}

\begin{abstract}
This paper presents an analysis methodology for establishing the demand stability of the planning environment faced by a company and the impact on the stability from changes to sales order. The methodology focuses on three critical planning parameters derived from customer orders: product mix, volume, and order sizes. Furthermore, the methodology links the delivery performance of a company to the changes made to sales orders. Based on a test case application of the methodology, it is concluded that by accepting changes, the demand faced by the case company has become more unstable on product mix, volume, and the number of order lines per period, while some added stability has been achieved with regards to the order size distributions. Ultimately, by applying the methodology to the case company, it is found that by changing the sales orders, the company does not improve the delivery performance.
\end{abstract}

Key words: Business Intelligence, diagnostics, Decision Support Systems, Performance Improvement Systems.

\section{Introduction}

The main challenge in today's businesses is not getting enough information to make qualified decisions, but rather structuring the information already available in a manner that facilitates pro- and reactive actions to improve the performance of the business. Nowadays, manufacturers compete not only on the prices of supplied products but also on the services supported to the customers. On-time delivery is one of the most important services that a manufacturer has to provide and thus on-time delivery becomes a critical performance measure. The importance of this increases if the manufacturer is placed early in a supply chain. The lateness of the delivery of an upstream supplier chain affects the plans of all downstream companies and the total cost of supply chain increases.

In manufacturing planning and control literature, much attention is given to the terms volume and product mix $[4,25]$. These are often seen as the critical parameters (together with the competitive priorities; quality, flexibility, reliability, and speed) when designing and evaluating supply chain or manufacturing planning and control systems. Furthermore, it is known that many companies focus in some manner on On-Timein-Full (OTIF) delivery of customer orders as their main performance goal [16]. Despite extensive literature on this topic, very little attention has been given to the connection between delivery performance and the stability of the planning environment in the form of the demand faced by the manufacturer. In order to establish this connection, this research investigates the impact of changes to sales order lines on the stability of the planning environment and links these changes to the delivery performance of a company.

It is known that the delivery performance is much affected by the frequency and type of changes to the production schedule, especially so in Make-To-Order (MTO) manufacturers, where each customer order is directly linked to the production schedule and it is difficult to get high delivery reliability [4]. As product mix and volume stability are critical in determining stability of the schedule, they should by definition also significantly influence the delivery performance. When these two factors are unstable, the manufacturer has to reschedule production activities or reduce the process lead time in order to meet the delivery requirement.

However, rescheduling the production activities and reducing the process lead time are costly or even infeasible. Another often overlooked element derived from volume and mix is the order size distributions. The distribution of order sizes, both in the form of average order size, number of orders, and variation in order size are critical as they directly impact the need for setup changes and thereby also the utilization and throughput of a manufacturing system. Furthermore, unstable order sizes will tend to indicate that the total demand for individual products is unstable.

\footnotetext{
${ }^{1}$ Corresponding author
} 
The motivation for this research is the long-term development of a complete diagnostic methodology that considers and enables diagnosis of the manufacturing planning and control system, by examining the inputs and changes to the system. In this context, the paper presents a step towards developing a comprehensive analysis methodology for identifying root causes for poor delivery performance. The paper is an extended version of a paper presented at the Industrial Engineering and Systems Management (IESM) 2011 in Metz [20] and focuses on three critical planning parameters; product mix, volume, and order sizes and presents a number of methods to analyze these areas. Specifically, the analysis methodology focuses on establishing the stability of the planning environment faced by the company in the form of demand and the impact of changes to sales order lines on the stability. A stable planning environment is in this context considered to have the following attributes:

- the product mix is stable, that is, the product mix does not vary from planning period to period,

- the demand is stable, that is, the demand is constant in volume from planning period to period,

- the order sizes are constant or follow a symmetric distribution.

An order is a set of requirements on the volume of different products and the delivery deadline of each type of product. Basically, the delivery deadline of each product type can vary. A requirement on volume and due date of each product type in an order is defined as an order line. This paper likewise introduces three different OTIF delivery performance measures that give a ratio of order lines, volume, and revenue, respectively, satisfactorily delivered OTIF.

These measures are chosen in a manner ensuring that they can be applied in various industries and companies. The main aim of the presented research is to establish both the stability of the demand faced by a company and to establish whether or not the company is stabilizing or destabilizing the planning environment by accepting or instigating changes to customer orders, thereby potentially affecting the delivery performance. Changes to customer orders are especially significant when diagnosing the actual performance of a manufacturing system and the supporting business processes.

The remainder of the paper is structured as follows. First, a literature review discussing the main parameters product mix, volume, and order sizes is presented. Second, an analysis methodology focusing on these areas is outlined. Following this is a paragraph on a data gathering framework and a case application of the methodology. Finally, conclusions and future research are presented.

\section{Literature review}

The design choices presented here are primarily related to the market being addressed and to some extent, the internal capabilities of a company. Delivery performance is investigated in some papers [4, 14, 23]. Brown et al. (2001) measure the effects of inventory inaccuracy in Material Requirements Planning (MRP) inventory and delivery performance for lot-for-lot and fixed-order-quantity policies by using simulation [4]. Lane and Szwejczewski (2000) investigated the relative importance of planning and control systems to achieve good delivery performance. They found that a responsive planning and control system is significantly more important than worker flexibility and quick changeover in achieving good delivery performance for MTO manufacturers [14]. Stefansson et al. (2009) proposed a computationally efficient procedure for production plans and schedules under uncertain and varying demand conditions for reducing the risk of delayed delivery in MTO production [23].

Many of the main design criteria deal with the relative volatility of the demand faced by the company, that is, the volatility of the volume and of the product mix. Normal design practices state that for volatile product mixes, the customer order decoupling point is moved backward $[4,13,21]$. In general, a number of parameters can be identified that are critical when establishing which manufacturing planning and control scheme to follow in a given situation. These can be categorized into internal and external factors.

The internal factors include, for example, the resources available to the company, the layout of production, etc. The external can be portioned into down-stream and up-stream influences. This paper focuses on the downstream influences on the manufacturing planning and control system. The down-stream influences on the manufacturing planning and control system are driven by the market faced by the company and the position of the company on this market. These market conditions in practice manifest for the planning environment in the form of: volume, product mix, and order size volatility. 
Certain criteria of stability for product mix and volume stability have been proposed and tested in literature, see for example [17].

\subsection{Product mix stability}

Product mix flexibility is often described in the terms of how cheaply a given product mix can be produced [11]. Thus the flexibility term is often related to a number of internal attributes of the manufacturing systems and the suggested measures are as such related to the internal cost structure of the company [7].

However, these measures as such state nothing of the inherent stability of a given product mix, but only the response of the manufacturing system to a given mix. Some limited work has been presented on a number of measures for establishing the stability of a product mix [17]. These are presented and briefly discussed below. From Nicholas [15], it is also known that the product mix has importance for the ability to balance production lines and that a more volatile/unstable product mix results in higher buffering costs. Thus, a stable product mix from period to period is desirable.

Some issues of unstable product mix (e.g. raw material purchasing) can be addressed through forecasting the product mix per period accurately. However, the manufacturing system as such is still designed with a specific product mix in mind, and deviating too far from this will cause an increase in operating costs or poor delivery performance.

\subsection{Volume stability}

Volume stability, both in the volatility of volume and the number of orders per period, has a significant impact on the performance of manufacturing systems. In theory, two manufacturing strategies exist to deal with volume instability, chase or level [26].

The chase strategy involves buffering (in any number of ways) to enable matching the variance in volume from period to period. In practice, this means having excess inventory and capacity available to absorb deviations from the expected mean volume per period.

The leveling strategy assumes that the volume can be leveled between planning periods, through moving delivery dates and quantities. In practice, this can be undesirable due to customer expectations and the market conditions faced by the company. Studies by, for example, Ceryan and Koren (2009) address the impact of demand volatility and the impact of this on the design of a manufacturing system [6]. The conclusion is straightforward, the more volatile the demand, the better the higher cost and flexible manufacturing system performs. In changeover heavy manufacturing environments, the volatility of the number of order lines per period can substitute the volatility of volume.

\subsection{Order size stability}

Order sizes are a critical parameter when designing manufacturing environments [15]. The number of orders and the distribution of the order sizes are critical for a number of issues.

First, to facilitate the aggregation and disaggregation of plans a number of assumptions are made [3] with regards to the orders handled by the system. The assumption is a one-to-one relationship in aggregation and disaggregation [12]. As a result, order sizes and the number of orders per period are assumed to be constant, to facilitate calculation of time needs for changeovers and the number of changeovers needed per planning period and thus the expected throughput rate of the system. If this is not the case, the disaggregation of plans may result in suboptimal or even infeasible disaggregate plans.

Second, to achieve a proper line balancing, the order sizes should either vary in a predictable independent identically distributed (i.i.d.) manner or be stationary over time [15]. In general, the consensus in literature is either to assume a constant number of orders and order size within a planning period or to assume that the order sizes follow a known symmetrical distribution and are i.i.d.

\subsection{Current state of performance measurement reporting - Business Intelligence/Diagnostics}

Through the last decade, Business Intelligence systems have emerged as an important tool in industry to track performance and to report this to managers. Basically, Business Intelligence systems assist in creating a dynamic and easy-to-understand overview on the vast amount of data available from the IT-systems within the company. 


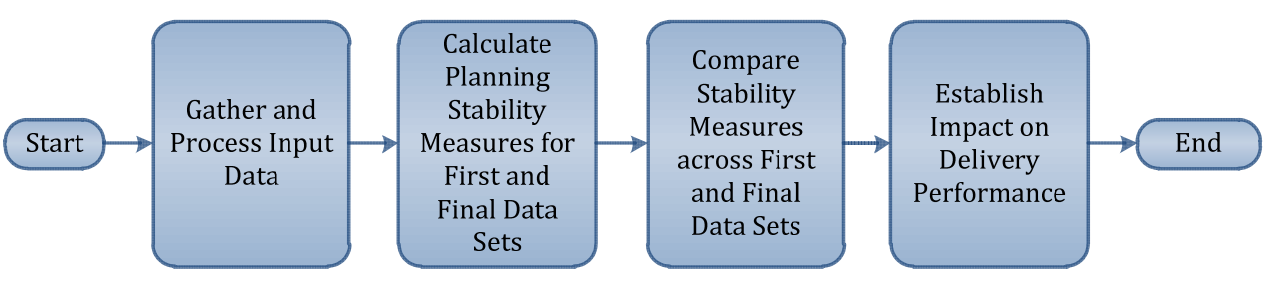

Figure 1. Flow chart of analysis methodology

Business Intelligence systems are often used in performance management as a tool for automatically calculating and communicating performance measures to selected users of the systems, typically management.

This allows defined performance measures to be used in performance management activities, in terms of a set of performance indicators, which can be narrowed down to a set of key performance indicators. Key performance indicators thus assist in identifying areas of the business where performance is lower or greater than expected, that is, differing from a target value [7].

Although being an important enabler of monitoring performance effectively, today's Business Intelligence tools are, however, limited to only identifying areas with performance issues, not the underlying causes. The job of explaining "why" and "how", that is, diagnosing performance issues occur lies within the scope of manual interpretation and evaluation of measurement results from the Business Intelligence system, and can be expensive, tedious, and subject to errors [22].

Automated interpretation and evaluation concepts to move from Business Intelligence towards a proactive diagnostic approach have been successfully applied to specific domains within companies, such as finance [10] and productivity [22]. These attempts reveal that it is possible to automate the diagnosing activities. However, current literature does not give any indication for a generic framework for diagnosing delivery performance issues, or operational performance issues related to manufacturing companies.

The aim of this paper is to some extent remedy this inadequacy, by exploring some of the immediate potential causes to poor delivery performance, that is, unstable planning environment, including changes to accepted sales orders, and combine this information with the performance observations. The value added to traditional Business Intelligence added from this diagnostic approach quantifies the effect of known causes enabling filtering with a significance level. In the follow- ing paragraph, an analysis methodology that can be automated and used for diagnostics in a generic manufacturing environment is presented.

\section{$3 \quad$ Analysis methodology}

In Figure 1, the 'first data set' means the information of the original orders from the customer. After that, these data can be changed based on the negotiations between the company and its customers. At the end of these negotiations, the data set is fixed, which means that there is no more change.

The fixed data set is called the 'final data set' in this paper. The analysis methodology illustrated in Figure 1 consists of a number of steps.

The first step includes gathering and preprocessing the input data for the methodology. This step includes logging the changes to sales lines, identifying the delivery dates, quantities, and product ID. This allows tracking changes and evaluating the impact on the relevant parameters identified in section 2 .

The second step includes sequentially calculating the product mix, volume, and order size stability for respectively the first and final promised delivery dates and quantities for all order lines included in the analysis. This step is conducted with user defined time windows - for example, the time window for comparison of stability can range according to the size of the data set and the requirements of the planning environment.

The third step is the comparison of stability on all criteria between the first promised delivery date and quantity for each sales line and the final (before delivery actually takes place) promised delivery date and quantity for each sales order line.

The last step in the analysis is the establishment of the impact of changes to sales orders on delivery performance. 
The results of the analysis will then answer the following:

1) are the changes to the sales orders improving/degrading the stability of the planning environment?

2) are the changes to sales orders resulting in a better/worse delivery performance?

This is done through investigating whether orders with on-modified delivery dates and/or quantities have a lower delivery performance than orders that have been changed.

The proposed analysis methodology investigates the following elements: product mix, volume, and order size stability, OTIF delivery performance, and the impact of changes to delivery performance. The analysis methodology relies on data gathered directly from the database of any Enterprise Resource Planning (ERP) system and enriched by a database containing all transactions and changes to sales orders.

\subsection{Measurement of product mix stability}

Nielsen et al. [17] present a number of measures to establish the stability of a product mix. These measures are shown below.

$$
\text { Variation of ratio }=\frac{\sum_{i \in n} \frac{\sigma_{i, t}}{x_{i, t}}}{n}
$$

Where $x_{i, t}$ and $\sigma_{i, t}$ are respectively the mean ratio of sales and standard deviation of the ratio of sales for the product $i$ over the whole time period with the time window of length $t . n$ is the total number of products in the whole set. The ratio of sales is defined as the ratio between the sale of product $i$ and the total sale of all products. If a product's sales are completely stable, the $\sigma_{i, t} / x_{i, t}$ ratio is zero. So for the completely stable product mix, this indicator should be zero. Due to the inclusion of a variance term, this indicator will tend to react more to large changes in the ratio of sales for a given product.

$$
\text { Relative span of rank }=\frac{\sum_{i \in n} \frac{\operatorname{Max}\left(R_{i, t}^{*}\right)-\operatorname{Min}\left(R_{i, t}^{*}\right)}{n}}{n}
$$

Where $\mathrm{R}_{\mathrm{i}, \mathrm{t}}$ is a vector of the product $i$ 's ranks with the time window length $t$. Rank is calculated in descending order, so that the product with the highest ratio of sales for a given time window is given rank 1. This criterion establishes the average relative range of ranks a product with a given time window size. This indicator should likewise be zero for a completely stable product mix. This criterion tends to punish product programs where many products are introduced and phased out. Thus this indicator can also be considered interesting when analyzing product lifecycles in relation to changes in product mix.

$$
\begin{aligned}
\text { Inclusion } & =\frac{\text { Numberof occurencesof non includedproducts }}{\text { Total numberof occurences }} \\
& =\sum_{i} \frac{\sum_{j} Y_{i, j}}{t}
\end{aligned}
$$

This indicator describes how many times a given product is not in the product mix with a given time window. If product $i$ is not in the product mix in period $j$, than $Y_{i, j}=1$; otherwise, $Y_{i, j}=0$. This indicator should likewise be zero for a completely stable product mix, indicating that all the products are sold in all time windows.

\subsection{Measurement of volume stability}

To determine the variation in volume, the wellestablished term coefficient of variance $\left(\mathrm{CV}^{\mathrm{V}}\right)$ is used [used in e.g. $(1,25)$ ]. This term is simply:

$$
C V_{j}^{V}=\frac{\sigma_{j}^{V}}{\mu_{j}^{V}}
$$

Where $\mu_{j}^{V}$ is the sample mean of the volume per period of length $j$ and $\sigma_{j}^{V}$ is the standard deviation of the observed volume per period of length $j$. A similar term coefficient of variance for the number of Order Lines $\left(\mathrm{CV}^{\mathrm{OL}}\right)$ is introduced. This term is simply:

$$
C V_{j}^{O L}=\frac{\sigma_{j}^{O L}}{\mu_{j}^{O L}}
$$

Where $\mu_{j}^{O L}$ is the sample mean number of Order Lines per period of length $j$ and $\sigma_{j}^{O L}$ is the standard deviation of the observed number of order lines per period of length $j$. For both $C V_{j}^{V}$ and $C V_{j}^{O L}$ a low value indicates low variation in respectively the volume sold and the number of order lines per period.

\subsection{Measurement of order size stability}

To measure the order size volatility, a number of standard statistical methods will be used. These include again, coefficient of variance of order size $\left(\mathrm{CV}^{\mathrm{O}}\right)$, kurtosis and skewness of the distribution of the order sizes in each period and the coefficient of variance for the average order size $\left(\mathrm{CV}^{\mathrm{AO}}\right)$ over all periods. 
Likewise, the independence of the order sizes' distributions is checked. In this manner, all the assumptions regarding the distributions and behavior of the order sizes is investigated using autocorrelation (Box and Jenkins, 1970).

Coefficient of variance of order size

$$
C V_{j}^{O}=\frac{\sigma_{j}^{o}}{\mu_{j}^{O}}
$$

Where $\mu_{j}^{O}$ is the sample mean of order size in period $j$ and $\sigma_{j}^{o}$ is the sample standard deviation of the order size in period $j$.

Coefficient of variance of average order size

$$
C V^{A O}=\frac{\sigma^{A O}}{\mu^{A O}}
$$

Where $\mu^{A O}$ is the sample mean of average order size in a given time window $t$ and $\sigma^{A O}$ is the sample standard deviation of the order size in a given time window $t$.

\subsection{Linking delivery performance to changes in the planning environment}

After deriving the measures for the planning stability, that is, stability of product mix, volume, and order

$$
\begin{aligned}
& \text { R-OTIF }=\frac{\text { Total revenue delivered on time }}{\text { Total revenue delivered }}=\frac{\sum_{i} Q_{i} R_{i}}{\sum_{n} Q_{n} R_{n}} \\
& \text { V-OTIF }=\frac{\text { Volume delivered on time }}{\text { Total volume delivered }}=\frac{\sum_{i} Q_{i}}{\sum_{n} Q_{n}} \\
& \text { OL-OTIF }=\frac{\text { Number of order lines delivered on time }}{\text { Total number of order lines delivered }}=\frac{\sum_{i} O L_{i}}{\sum_{n} O L_{n}} \\
& \text { where } i \in \text { set of order lines delivered ontime } \\
& \quad n \in \text { all delivered order lines } \\
& \quad Q_{i} \text { is the volume of an order line } i \\
& R_{i} \text { is the revenue per unit of product according to order line } i \\
& O L_{i} \text { is the order line } i
\end{aligned}
$$

The three delivery performance measures have the advantage that they can be compared across markets, products, companies, industries, etc. since they are unitless. If absolute terms such as lead time or cost of delivery were used, comparisons across industries or even business areas within the same company become difficult. The aim of this research is to work towards a generic methodology, this must by necessity imply the need for generic measures of delivery performance. Like any analysis method, the presented methodology has limitations in application. First, the methodology requires a transaction-rich environment to give precise answers. Terms such as $\mathrm{CV}^{\mathrm{V}}, \mathrm{CV}^{\mathrm{OL}}$, product mix stability, and order size stability as calculated in this context improve in precision as the number of observations increase. A further application limitation must be recognized. 
Table 1. An overview of the input data used for the case application of the analysis methodology

(The analysis uses 10 weeks of data; the values in the table below indicate the total for the whole 10 -week period)

\begin{tabular}{|l|c|c|c|}
\hline \multicolumn{1}{|c|}{ Data set } & $\begin{array}{c}\text { Number of unique prod- } \\
\text { ucts sold in total }\end{array}$ & $\begin{array}{c}\text { Total number of sales } \\
\text { lines }\end{array}$ & $\begin{array}{c}\text { Total volume of products prom- } \\
\text { ised for sales }\end{array}$ \\
\hline Original sales orders & 107 & 686 & 1861 \\
\hline $\begin{array}{l}\text { Final sales orders after } \\
\text { changes }\end{array}$ & 113 & 719 & 1568 \\
\hline
\end{tabular}

Table 2.The product mix stability criterion for 1- and 2-week aggregations of sales,

for respectively the original and the last promised delivery dates and quantities

\begin{tabular}{|l|c|c|c|c|c|c|c|c|}
\hline & \multicolumn{2}{|c|}{$\begin{array}{c}\text { Original sales } \\
\text { order }\end{array}$} & \multicolumn{2}{c|}{$\begin{array}{c}\text { Final sales orders } \\
\text { after changes }\end{array}$} & \multicolumn{2}{c|}{ Deviation } & \multicolumn{2}{c|}{ Relative deviation } \\
\hline & $\begin{array}{c}1 \\
\text { week }\end{array}$ & $\begin{array}{c}2 \\
\text { weeks }\end{array}$ & $\begin{array}{c}1 \\
\text { week }\end{array}$ & $\begin{array}{c}2 \\
\text { weeks }\end{array}$ & $\begin{array}{c}1 \\
\text { week }\end{array}$ & $\begin{array}{c}2 \\
\text { weeks }\end{array}$ & $\begin{array}{c}1 \\
\text { week }\end{array}$ & $\begin{array}{c}2 \\
\text { weeks }\end{array}$ \\
\hline Inclusion criterion & 0.71 & 0.57 & 0.72 & 0.61 & -0.01 & -0.04 & $-1.4 \%$ & $-7.0 \%$ \\
\hline Relative span of rank criterion & 0.84 & 0.75 & 0.85 & 0.73 & -0.01 & 0.02 & $-1.2 \%$ & $2.7 \%$ \\
\hline Variation of ratio criterion & 2.21 & 1.64 & 2.21 & 1.66 & 0.00 & -0.02 & $0.0 \%$ & $-1.2 \%$ \\
\hline
\end{tabular}

The analysis methodology should be applied to sales data for products with similar impact on the manufacturing planning and control system. A natural discrimination would be products from the same product family. However, this is not an unreasonable limitation since indiscriminate application of the methodology without limiting the scope of analysis will also render the interpretation of results difficult if not impossible

\section{$4 \quad$ Case test of methodology}

The analysis methodology has been implemented in a medium-sized manufacturing company. The company accepts changes to sales orders both initiated from customer requests and when production constraints occur, to create a more feasible production plan for an OTIF delivery. In the context of this research, the cause of changes to sales orders is not logged since only the impact on the planning environment is considered. Currently, the company has no knowledge of how the number of changes affects their delivery performance or performance in general.

To assist in providing this information, a data logger prototype has been developed and implemented and has been running at the case company for several months. The prototype is based on a generic framework applicable in any ERP-environment [9].
The prototype works by identifying changes made to sales orders on a daily basis by comparing the two latest versions of the same order line. Each subsequent change to a sales order line is then logged. In this way, it is possible to identify how often products are delivered exactly as the customer requested it initially and how often and what changes are made to each sales order line [9].

For the purpose of this case test of the analysis methodology, the main product family in the company is selected for analysis. A total of 10 weeks of full delivery and order promising is available for the test. Only periods for which all changes have been registered and all sales order lines have been delivered are desirable for the analysis. Two levels of aggregation of time periods are chosen for investigation, 1 and 2 weeks.

Table 1 shows the number of orders, the number of unique products (SKUs1) sold and the total volume of the orders in respectively the first promised and last promised delivery dates and quantities. As can be seen from Table 1, for better clarity, information aggregates show some changes have occurred to the sales order lines. Six new products have been introduced to the mix, the number of order lines has increased by $5 \%$ and the volume has decreased by $16 \%$.

\footnotetext{
${ }^{1}$ stock-keeping units
} 
Table 3. Volume and number of order lines per period comparison using both 1 and 2 weeks of aggregation

\begin{tabular}{|c|c|c|c|c|c|c|c|c|}
\hline & \multicolumn{2}{|c|}{$\begin{array}{c}\text { Original sales } \\
\text { orders }\end{array}$} & \multicolumn{2}{c|}{$\begin{array}{c}\text { Final sales orders } \\
\text { after changes }\end{array}$} & \multicolumn{2}{c|}{ Deviation } & \multicolumn{2}{c|}{ Relative deviation } \\
\hline & $\begin{array}{c}1 \\
\text { week }\end{array}$ & $\begin{array}{c}2 \\
\text { weeks }\end{array}$ & $\begin{array}{c}1 \\
\text { week }\end{array}$ & $\begin{array}{c}2 \\
\text { weeks }\end{array}$ & $\begin{array}{c}1 \\
\text { week }\end{array}$ & $\begin{array}{c}2 \\
\text { weeks }\end{array}$ & $\begin{array}{c}1 \\
\text { week }\end{array}$ & $\begin{array}{c}2 \\
\text { weeks }\end{array}$ \\
\hline $\mathrm{CV}^{\mathrm{V}}$ & 0.74 & 0.45 & 0.86 & 0.58 & -0.12 & -0.13 & $-16.2 \%$ & $-28.9 \%$ \\
\hline $\mathrm{CV}^{\mathrm{OL}}$ & 0.37 & 0.32 & 0.49 & 0.41 & -0.12 & -0.09 & $-33.0 \%$ & $-29.5 \%$ \\
\hline
\end{tabular}

Table 4. The kurtosis, skewness, and covariance of order size in 10 weeks

\begin{tabular}{|c|c|c|c|c|c|c|c|c|c|}
\hline \multirow{2}{*}{ Period } & \multicolumn{3}{|c|}{ Kurtosis } & \multicolumn{3}{c|}{ Skewness } & \multicolumn{3}{c|}{ CV $^{\mathrm{O}}$} \\
\cline { 2 - 9 } & $\begin{array}{c}\text { First } \\
\text { data } \\
\text { set }\end{array}$ & $\begin{array}{c}\text { Final } \\
\text { data } \\
\text { set }\end{array}$ & Difference & $\begin{array}{c}\text { First } \\
\text { data } \\
\text { set }\end{array}$ & $\begin{array}{c}\text { Final } \\
\text { data } \\
\text { set }\end{array}$ & Difference & $\begin{array}{c}\text { First } \\
\text { data } \\
\text { set }\end{array}$ & $\begin{array}{c}\text { Final } \\
\text { data } \\
\text { set }\end{array}$ & Difference \\
\hline Week 1 & 2.33 & 7.76 & $233 \%$ & 1.88 & 2.75 & $46 \%$ & 0.46 & 0.89 & $92 \%$ \\
\hline Week 2 & 30.13 & 6.97 & $-77 \%$ & 5.59 & 2.58 & $-54 \%$ & 4.94 & 1.26 & $-74 \%$ \\
\hline Week 3 & 21.18 & 9.67 & $-54 \%$ & 4.39 & 3.04 & $-31 \%$ & 2.25 & 1.02 & $-55 \%$ \\
\hline Week 4 & 12.08 & 26.62 & $120 \%$ & 3.46 & 4.87 & $41 \%$ & 0.69 & 1.48 & $113 \%$ \\
\hline Week 5 & 60.74 & 86.88 & $43 \%$ & 7.38 & 8.86 & $20 \%$ & 2.99 & 4.03 & $35 \%$ \\
\hline Week 6 & 42.36 & 15.15 & $-64 \%$ & 6.13 & 3.77 & $-39 \%$ & 1.27 & 0.56 & $-56 \%$ \\
\hline Week 7 & 17.80 & 7.69 & $-57 \%$ & 4.08 & 2.76 & $-32 \%$ & 0.98 & 0.88 & $-9 \%$ \\
\hline Week 8 & 6.29 & 9.70 & $54 \%$ & 2.58 & 2.67 & $3 \%$ & 1.17 & 0.77 & $-34 \%$ \\
\hline Week 9 & 39.80 & 35.10 & $-12 \%$ & 6.08 & 5.69 & $-6 \%$ & 1.49 & 1.28 & $-14 \%$ \\
\hline Week 10 & 28.98 & 10.60 & $-63 \%$ & 4.82 & 3.15 & $-35 \%$ & 1.06 & 1.12 & $5 \%$ \\
\hline
\end{tabular}

This indicates that significant changes have been made to the sales order lines. The results of applying the methodology to the case and the interpretation of these results are presented below.

Table 2 shows the three measures of product mix stability for each of the data sets for 1- and 2-week period lengths. The 'Original sales orders' and 'Final sales orders after changes', respectively, cover the first promised delivery date and quantity and the final after all changes have been made to the sales orders.

As expected from theory of aggregation, the product mix is more stable when the time period considered is longer $[18,24,27]$. This is seen from Table 2 when time periods of two weeks are compared, they are more stable than the product mix on a week-to-week basis.

The deviations in indicators are found by subtracting the value of the indicator for the last promised set of sales order lines from the original set. A negative value indicates more unstable behavior in the last promised set. Four out of six product mix stability indicators are more unstable in the changed sales order line set than in the original and one is unchanged. This indicates that the company through changes to promised delivery dates and quantities is facing a more unstable product mix.

Table 3 contains the values for $C V_{1}^{V}, C V_{2}^{V}, C V_{1}^{O L}$ and $C V_{2}^{O L}$ for the two data sets. The subscript denotes the length of the time period. Similar to the product mix, longer time periods give more stable behavior for both data sets. Similarly, the negative deviation values in Table 3 indicate that the final promised sales order lines destabilize the planning environment. From the table, it can be seen that for all counts of $\mathrm{CV}^{\mathrm{V}}$ and $\mathrm{CV}^{\mathrm{OL}}$ the original promised sales order lines give a more stable planning environment. $C V_{1}^{V}$ and $C V_{2}^{V}$ increased $16.2 \%$ and $28.9 \%$, respectively, and $C V_{1}^{O L}$ and $C V_{2}^{O L}$ increased $33.0 \%$ and $29.5 \%$, respectively, in the last promised set of sales order lines. 
Table 5. Autocorrelation measurement for first and final data sets with different lags

\begin{tabular}{|c|cccc|cccc|}
\hline \multirow{2}{*}{ Period } & \multicolumn{4}{|c|}{ First data set } & \multicolumn{4}{c|}{ Final data set } \\
\cline { 2 - 9 } & Lag=1 & Lag=2 & Lag=3 & Lag=4 & Lag=1 & Lag=2 & Lag=3 & Lag=4 \\
\hline Week 1 & -0.131 & 0.065 & -0.147 & -0.256 & 0.212 & -0.102 & -0.092 & -0.029 \\
Week 2 & -0.031 & -0.032 & -0.033 & -0.013 & 0.418 & 0.310 & 0.335 & 0.253 \\
Week 3 & 0.095 & -0.065 & 0.171 & 0.049 & 0.040 & -0.018 & 0.010 & -0.146 \\
Week 4 & -0.031 & -0.083 & 0.018 & -0.008 & 0.452 & -0.027 & -0.041 & 0.052 \\
Week 5 & 0.245 & 0.040 & 0.005 & -0.015 & 0.210 & 0.006 & 0.016 & -0.005 \\
Week 6 & -0.062 & 0.014 & 0.009 & -0.041 & -0.074 & -0.044 & 0.017 & -0.079 \\
Week 7 & 0.082 & 0.137 & 0.039 & -0.017 & 0.080 & 0.146 & 0.080 & -0.050 \\
Week 8 & 0.322 & 0.099 & -0.122 & -0.045 & 0.468 & 0.255 & 0.102 & 0.159 \\
Week 9 & -0.027 & -0.024 & 0.003 & -0.021 & -0.031 & -0.053 & 0.058 & 0.021 \\
Week 10 & -0.034 & -0.006 & 0.111 & 0.007 & 0.263 & 0.195 & -0.080 & -0.139 \\
\hline
\end{tabular}

Table 6. Pearson correlation measures between the number of changes per sales order and the three

(R-, V- and OL-OTIF) delivery performance measures and their corresponding significance levels.

\begin{tabular}{|l|c|c|c|}
\hline & R-OTIF & V-OTIF & OL-OTIF \\
\hline Correlation & 0.0072 & -0.0162 & 0.0139 \\
\hline$p$-value & 0.93 & 0.85 & 0.87 \\
\hline
\end{tabular}

This strongly indicates that the company is not leveling demand over the week or bi-weekly time periods by changing delivery dates and quantities. Likewise, the deterioration in the $\mathrm{CV}^{\mathrm{OL}}$ values indicates that the company will incur a larger variation in the number of setups and changeovers. This can make estimating packing capacity and the time needed for handling changeovers more difficult. In all, the volatility of both volume and number of order lines increases due to the changes to sales order lines.

Table 4 shows that the order size of final data set is more stable than that of the first data set, indicating that the company has more stable order size distributions within their weekly planning buckets.

The coefficient of variance of average weekly order size of first and final data sets are 0.701 and 0.32 , respectively. This supports the conclusion that the order sizes are in the final data set stemming from more symmetrical distributions. However, it is noteworthy that these more symmetrical order size distributions have not been achieved through leveling the overall volume.

While the data presented in Table 4 indicate less variation in order sizes within the weekly time buckets, the results presented in Table 5 indicate that this has been achieved through ordering the orders, so that large orders to a higher extent follow large orders. This is indicated through only a few periods for the first data set show dependently distributed order sizes, while, the situation is different for the final data set.

With lag $=1$, there are 6 weeks with a high autocorrelation value indicating dependence of observations. The periods, which are not independent in first data set, are also not independent in final data set. Hence, it can be concluded that there is a trade-off between the stability and the independence of order sizes.

The final analysis is the investigation of the relationship between the number of changes to sales order lines and the delivery performance. The results of the correlation tests can be seen in Table 6 below. 
Table 6 shows both the Pearson correlation measures between the changes to sales order lines and the delivery performance and the significance levels. Through investigation of whether orders with many changes have a better delivery performance than orders with no/few changes, it is possible to determine if the delivery performance is improved by accepting or instigating changes to sales orders. The results show that there is no connection between the delivery performance and the changes performed to the sales order lines. This goes for all three OTIF measures.

The conclusion is that the company is not improving its delivery performance by changing the delivery dates and quantities, that is, orders with changes to them have no statistically better delivery performance than those with no/few changes.

The overall conclusion from the application of the methodology to the case can be summarized in the following points. First, the demand faced by the company has through changes become more unstable on product mix, volume, and the number of order lines per period. However, there is a significant improvement in the order size stability, indicating that orders have become slightly better grouped from the perspective of changeovers and line balancing. There is no significant indication that the company improves their delivery performance by changing the delivery dates and quantities of their sales orders.

The conclusion must be that by implementing changes to sales orders, the case company actually instigates a more unstable planning environment. This also explains why there is no significant improvement in delivery performance for products with many changes to sales order lines. Thus the company rather than gain benefits from the changes, actually incur a more unstable situation. This must by necessity mean that the company is incurring higher than necessary operating costs [6].

Therefore, the recommendation to the company must be (if changes to sales orders is not an order qualifier / winner) to aim at not changing their sales order lines, if they wish to have a more stable planning environment or changing them in another manner than in the current setup. In the same way, assuming that all changes are based on customer change request, the information provided by applying the analysis methodology can be used in negotiations with custom- ers to clarify to the customer the impact of changes to the cost for the customer.

\section{Conclusions and further research}

While the parameters product mix, volume, and order size stability to some extent is covered in manufacturing planning and control literature, it can be concluded that they have not been linked in a comprehensive framework to establish the stability of the planning environment. From the literature review, it is established that, in general, the more stable the planning environment, the lower the operating costs for the manufacturing system with a given service level. The parameters to a large extent depend on the demand faced by a company, manifested through sales orders. Thus a rational approach would be to aim at stabilizing the planning environment, a concept recognized from, for example, Lean and Six Sigma literature, by eliminating variance. The conclusion from the literature review is thus two points. First, that a stable planning environment is preferable to ensure low operating costs at a given service level. Second, that any changes made to sales orders (whether they are internally or externally motivated) should serve to stabilize the planning environment rather than destabilize it.

This paper presents an analysis methodology aimed at establishing first, the stability of a given planning environment (based on demand data) and second, at determining whether changes to sales orders stabilize or destabilize the planning environment. The methodology addresses the topics product mix stability, volume and changeover stability, and the order size stability. The methodology then links these to changes in sales order lines and to the delivery performance.

Based on the presented case and the literature review, it is concluded that the analysis methodology is in a quantitative manner able to identify the stability of the demand being faced by a manufacturing environment. The conclusion is that the methodology can be used to establish the stability of the demand faced by a planning environment. Second, the methodology can be used as part of a diagnostics framework to identify root causes for poor planning performance and link these to changes in sales orders. This means that the methodology can be used to identify whether changes to the demand situation is stabilizing or destabilizing the planning environment. 
Future research will focus on testing the current methodology on data from several other manufacturing companies to enable cross-company comparison of performance and further validation of the diagnostics capability of the methodology. Furthermore, the diagnostic capabilities of the methodology will be developed towards a comprehensive diagnostics framework for planning performance.

\section{Acknowledgement}

The research presented in this paper is funded by the European Union via the EmpoSME and ValuePOLE projects, which, we kindly acknowledge. Further, we would like to thank the case company for its engaged interaction.

\section{References}

[1] Akkerman R., van Donk D.P. - Product mix variability with correlated demand in two-stage food manufacturing with intermediate storage [in] International Journal of Production Economics, Vol. 121, 2009, pp. 313-322.

[2] Axsäter S. - On the Feasibility of Aggregate Production Plans [in] Operations Research, Vol. 34, 1986, pp. 796-800.

[3] Axsäter S. - Aggregation of Product Data for Hierarchical Production Planning [in] Operations Research Vol. 29, 1981, pp. 74-756.

[4] Berry W.L., Hill T. - Linking Systems to Strategy [in] International Journal of Operations \& Production Management, Vol. 12, 1992, pp. 3-15.

[5] Brown K.L., InmanR. A., Calloway J.A. - Measuring the effects of inventory inaccuracy in MRP inventory and delivery performance [in] Production Planning \& Control: The Management of Operations, Vol. 12, 2001, pp. 46-57.

[6] Ceryan O., KorenY. - Manufacturing capacity planning strategies [in] CIRP Annals - Manufacturing Technology, Vol. 58, 2009, pp. 403-406.

[7] de Groote X. - Flexibility and product variety in lot-sizing models [in] European Journal of Operational Research, Vol. 75, 1994, pp. 264-74.

[8] Elbashir M.Z., Collier P.A., Davern M.J. - Measuring the effects of business intelligence systems: The relationship between business process and organizational performance [in] International Journal of Accounting Information Systems, Vol. 9, 2008, pp. 135-153.
[9] Eriksen T.S., Nielsen P., Steger-Jensen K. - Delivery Performance Diagnosis by use of Data Logging and Enrichment of Transactional Data [at] 12th International MITIP Conference,Aalborg, Denmark, 2010, pp. 110-121.

[10] Feelders A.J., Daniels H.A.M. - A general model for automated business diagnosis [in] European Journal of Operational Research, Vol. 130, 2001, pp. 623-637.

[11] Gong Z., Hu S.- An economic evaluation model of product mix flexibility [in] Omega, Vol. 36, 2008, pp. 852-64.

[12] Hax C., Meal H.C. - Hierarchical Integration of Production Planning and Scheduling. Massachusetts Institute of Technology, Operations Research Center, 1973.

[13] Jodlbauer H. - Customer driven production planning [in] International Journal of Production Economics, Vol 111, 2008, pp. 793-801.

[14] Lane R., Szwejczewski M. - The relative importance of planning and control systems in achieving good delivery performance [in] Production Planning \& Control: The Management of Operations, Vol. 11, 2000, pp. 422-433.

[15] Nicholas J.M. - Competitive Manufacturing Management. McGraw-Hill, Irwin, 1998.

[16] Nielsen P., Nielsen I., Steger-Jensen K. - An investigation of the volatility of volume and revenue for planning purposes [at] International Conference on Advances in Production Management Systems, Como, Italy, 2010.

[17] Nielsen P., Nielsen I., Steger-Jensen K. - The Relative Stability of a Product Mix [at] International Conference on Advances in Production Management Systems, Como, Italy, 2010.

[18] Nielsen P., Nielsen I., Steger-Jensen K. - Investigating the Implicit Assumptions of the Hierarchical Demand Planning Approach [at] IESM'2009, International Conference on Industrial Engineering and Systems Management, ÈcolePolytechnique Montréal, Canada, 2009.

[19] Nielsen P., Nielsen I., Steger-Jensen K. - Analyzing and evaluating product demand interdependencies [in] Computers in Industry, Vol. 61, 2010, pp. 869876. 
[20] Nielsen P., Eriksen T. - Towards an analysis methodology for identifying root causes of poor delivery performance [at] IESM 2011, International Conference on Industrial Engineering and Systems Management, Metz, France, 2011.

[21] Olhager J.O. - Strategic positioning of the order penetration point [in] International Journal of Production Economics, Vol. 85, 2005, pp. 319329.

[22] Rao M.P., Miller D.M., Lin B. - PET: An expert system for productivity analysis [in] Expert Systems with Applications, Vol. 29, 2005, pp. 300309.

[23] Stefansson H., Jensson P., Shah N. - Procedure for reducing the risk of delayed deliveries in maketo-order production [in] Production Planning \&
Control: The Management of Operations, Vol. 20, 2009, pp. 332-342.

[24] Theil H. - Applied Economic Forecasting [in] Vol. 4 of Studies in Mathematical and Managerial Economics. North-Holland Publishing Company, 1966.

[25] Tsubone H., Furuta H. - Replanning timing in hierarchical production planning [in] International Journal of Production Economics, Vol. 44, 1996, pp. 53-61.

[26] Vollmann W., Berry D., Whybark T.E., Jacobs F. Manufacturing Planning and Control for Supply Chain Management. McGraw-Hill, Singapore, 2005.

[27] Wijngaard J. - On Aggregation in Production Planning [in] Engineering Costs and Production Economics, Vol. 6, 1982, pp. 259-66. 